\title{
The Pattern of Seminal Fluid Analysis among Male Partners Attending an Infertility Clinic in a Nigerian Tertiary Health Institution
}

\author{
Amina Gambo Umar ${ }^{1}$, Abubakar Abubakar Panti1, Marcus Mbakwe'2, Yakubu Ahmed1, \\ Jamila Abubakar Garba², Daniel Chukunyere Nnadi1 \\ ${ }^{1}$ Department of Obstetrics and Gynaecology, Usman Danfodiyo University, Sokoto, Nigeria \\ ${ }^{2}$ Department of Obstetrics and Gynaecology, Usman Danfodiyo University Teaching Hospital, Sokoto, Nigeria \\ Email: *aminagamboobgy@gmail.com
}

How to cite this paper: Umar, A.G., Panti, A.A., Mbakwe, M., Ahmed, Y., Garba, J.A. and Nnadi, D.C. (2020) The Pattern of Seminal Fluid Analysis among Male Partners Attending an Infertility Clinic in a Nigerian Tertiary Health Institution. Open Journal of Obstetrics and Gynecology, 10, 957-967. https://doi.org/10.4236/ojog.2020.1070090

Received: April 12, 2020

Accepted: July 27, 2020

Published: July 30, 2020

Copyright $\odot 2020$ by author(s) and Scientific Research Publishing Inc. This work is licensed under the Creative Commons Attribution International License (CC BY 4.0).

http://creativecommons.org/licenses/by/4.0/

\begin{abstract}
Background: Semen analysis has remained an objective, inexpensive and readily available means of assessing male factor infertility. Aim and Objective: This study aims to determine the prevalence of male infertility, the types and semen quality among infertile couples attending infertility clinic at UDUTH, Sokoto. Materials and Method: This is a retrospective study carried out between January, 2012 to December, 2016. All case notes of infertile patients managed were retrieved The data obtained was analysed using SPSS version 20 and the results were presented in text, tables and charts. Results: Eight hundred and seventy-six out of 11,938 total gynaecological consultations over the study period were due to infertility, giving a prevalence of 7.3\%. Among them, $34.4 \%$ (320) accounted for male factor infertility. The age ranged between 22 to 75 years with a mean of 37.44 years \pm 7.44 . Majority, $50.2 \%$ were within the ages of $35-44$ years and up to $73.8 \%$ of them had at least secondary education and were mostly, $39.7 \%$ civil servants. Up to $75.4 \%$ had sperm abnormalities, among which 65\% (196/301) had primary infertility while, 35\% (105/301) had secondary infertility. About half of them (47.5\% (153/301)) had Azoospermia, $22.3 \%$ (67/301) Oligospermia and only 30.3\% (91/301) had a normal sperm count. More than half of them, 121/227 (53.3\% had multiple abnormalities). Conclusion: Male factor infertility contributes significantly to the burden of infertility in our environment. Therefore, there is the need to create awareness so that males fully participate in the evaluation, as the blames are mainly on the females.
\end{abstract}

\section{Keywords}

Seminal Fluid Analysis, Oligospermia,

Infertility Clinic Oligoasthenoteratozospermia 


\section{Introduction}

Infertility is the inability of a couple to conceive despite adequate, regular, unprotected intercourse of 12 months' duration [1]. On the other hand, male infertility is the inability of the male reproductive cells to produce mature, actively motile and functional spermatozoa in sufficient amount that will ensure fertilization of a released ovum in the fallopian tube [2]. Usually the women are blamed of infertile marriages, especially when the man is able to achieve erection and ejaculate [2]. Since the quality of seminal fluid cannot be physically assessed, the intervention of the medical laboratory is often sought [2]. The prevalence of infertility in the general population is $15 \%-20 \%$. Of these, male factor is responsible for $20 \%-40 \%$ [3] and female factors contribute $30 \%-40 \%$ while, both factors and unexplained causes account for $20 \%-40 \%$ each [4]. Infertility is both a urological and gynaecological problem worldwide, and it remains a sensitive issue in our environment and a source of social stigma [5] [6]. The prevalence of infertility is particularly high in sub-Saharan Africa, varying from $20 \%-40 \%$ in some parts of west Africa [2]. The world health organization reveals that the male reproductive capacity is deficient in not less than $50 \%$ of infertile couples in several countries of the world [2]. In Africa, up to $65 \%$ of gynaecological consultations are due to infertility [2], and it affects about $15 \%$ of couples, rendering nearly one out of each 6 childless [7]. Multiple sources of bias have served to distort assessment of the contribution of each gender to infertility, but men can be expected to contribute equally to women when it comes to whose gametes are faulty [7]. Accurate evaluation and treatment of the man become of great importance in addressing a significant health care issue [7].

Whereas, the effect of males' age on reproductive potential is yet to be confirmed, advancing male age appear to affect bulk seminal parameters and sperm DNA packaging to only a limited degree, allowing a male to father children well into his later years [7]. For the females, age is a critical predictor of reproductive potential especially when assisted reproductive technology (ART) is used [7].

A case control study of 200 from Dakha, Bangledash revealed an increased incidence of sexually transmitted infection among the cases compared to controls [8]. The author also reported that chronic prostatitis had limited influence on ejaculate variables but that approximately $10 \%$ of those that had acute epididymitis developed persistent azoospermia thereafter, and 30\% oligozoospermia. In another study, obstruction of the ducts can ensue, as can post-infectious disturbances of spermatogenesis [9]. With regards to smoking, the cases exceeded the controls in both in duration of smoking and number of sticks smoked per day, Highest number of controls was oligospermic (42.0\%); followed by, azoospermia (18.0\%), asthenozoospermia (16.0\%), teratozoospermia (4.0\%), and [8] concluded that smoking is a cause of semen abnormality. According to Delfing in 2007, Diabetes Mellitus has a negative impact in terms of sperm quality [9]. Vignon in 1991 demonstrated diabetes mellitus as a cause of higher sperm concentration and abnormal morphology with no difference in motility, and that many of these diabetic men had fathered children and the authors concluded that Diabetes Mellitus in itself 
was not a cause of sub-fertility [10]. According to a study done by Chia in Singapore in 2000, smoking, density of sperm and the viability of sperm were found to be significant risk factors for infertility among men [11]. In a study in Turkey, cigarette smoking found to be negatively correlated with progressive motility of sperm [12]. A study performed on 395 patients, the outcome showed that sperm concentration is not very much affected by smoking but the quality of sperm (sperm motility especially rapid liner movement) is grossly affected by smoking and that in turn influences the fertility status [13]. The study, conducted in Ibadan, Nigeria, revealed $27.3 \%$ of 824 subjects had abnormal semen analysis, among them asthenozoospermia was the most common (27.8\%) and 6.7\% had azoospermia. The most common combined abnormality was Oligo-zoospermia (25.5\%) while, Oligo-Asthana-teratozoospermia was found in $13.1 \%$ [13]. Another study in Nigeria, revealed $74 \%$ of sub fertile men were normozoospermic, while $16.19 \%$, $5.57 \%$ and $4.07 \%$ were azoospermic, necrozoospermic and asthenozoospermic respectively [14]. In Islamabad, a study showed, the Mean sperm concentration of $0 \mathrm{mil} / \mathrm{ml}$ in azoospermic, $6.7 \pm 1.7 \mathrm{mil} / \mathrm{ml}$. Another study on effect of hypertension on semen quality revealed that men with hypertension were found to be more likely to have one or more semen abnormalities compared to normotensive men. Moreover, compared to men without hypertension, the hypertensive arm demonstrated impaired semen parameters. Hypertensive men had a lower semen volume (2.1 mL vs. $3.0 \mathrm{~mL})$, sperm motility (41.0\% vs. $47.0 \%)$, total sperm count (103.8 vs. 147.0 million) and total motile sperm count (43.1 vs. 65.9) [15].

As Infertility constituted $15.7 \%$ of all gynaecological consultations in UDUTH [6]. This study is designed to assess the contribution of male infertility, types, quality of seminal fluid and associated factors among men partners that attended the gynaecological and urological clinics of UDUTH Sokoto.

\section{Materials and Methods}

This is a 5-year retrospective study where all male partners of infertile women who attended the infertility clinic of the Usmanu Danfodiyo University Teaching Hospital Sokoto (UDUTH) between 2012 to 2016 were included. A total of 320 patients were seen during the study period out of which 301 files were reviewed. from the gynaecology and urology clinics as well as the records department were retrieved. All the patients abstained from sexual intercourse or masturbation for a period of 3 - 5 days and avoided the use of antibiotics prior to sample collection. For more than 2 weeks Samples were collected into sterile screw capped plastic universal containers and transported to the laboratory within less than 1 hour of production while maintaining the sample at close to the body temperature $\left(37^{\circ} \mathrm{C}\right)$ as possible.

Relevant information including sociodemographic characteristics, possible risk factors that include; age, history of smoking, consumption of alcohol, diabetes mellitus, hypertension, sexually transmitted infection, mumps orchitis and trau$\mathrm{ma}$ /surgery to the groin. In addition to information regarding the type of infer- 
tility and the results of seminal fluid analysis were obtained from the previously documented review records. The data obtained was analyzed using SPSS version 20. The data were analyzed for frequencies, mean, Chi-square with level of significance set at less than 0.05. Ethical approval was granted from the hospital ethics and research committee.

\section{Results}

Eight hundred and seventy-six of 11,938 total gynaecological consultations over the study period were due to infertility, giving a prevalence of $7.3 \%$. Among them, $34.4 \%$ (320) accounted for male factor infertility. Out of 320 cases, 301 case notes were reviewed giving a retrieval rate $94 \%$. Their age ranged between 22 to 75 years with a mean of $37.44 \pm .7 .44$ years. Majority were between the age group of 35 - 44 years accounting for $50.2 \%$ and the least was 65 years and above (0.7\%). Most of them had at least secondary level of educated 220 (73.8\%) with 51.7\% having tertiary education and majority were civil servants constituting 119 (39.7\%) of the infertile population. Details of the respondent's sociodemographic characters are as in Table 1 below.

Table 1. Socio-demographic characteristics of participants.

\begin{tabular}{|c|c|c|}
\hline Variables & Frequency & Percentage (\%) \\
\hline \multicolumn{3}{|l|}{ Age } \\
\hline$<24$ & 3 & 1 \\
\hline $25-34$ & 97 & 32.2 \\
\hline $35-44$ & 151 & 50.2 \\
\hline $45-54$ & 43 & 14.3 \\
\hline $55-64$ & 5 & 1.7 \\
\hline$\geq 65$ & 2 & 0.7 \\
\hline \multicolumn{3}{|l|}{ Education } \\
\hline No formal & 76 & 25.5 \\
\hline Primary & 2 & 0.7 \\
\hline Secondary & 66 & 22.1 \\
\hline Tertiary & 154 & 51.7 \\
\hline \multicolumn{3}{|l|}{ Occupation } \\
\hline Unemployed & 1 & 0.3 \\
\hline Civil servants & 119 & 39.7 \\
\hline Farmers & 39 & 13 \\
\hline Self employed & 123 & 41 \\
\hline $\begin{array}{c}\text { Force } \\
\text { Bankers }\end{array}$ & 10 & $3 . .3$ \\
\hline Students & 1 & 0.3 \\
\hline Total & 8 & 2.7 \\
\hline Total & 301 & 100 \\
\hline
\end{tabular}


Majority, $65 \%$ of the couples were managed for primary infertility while, $35 \%$ had secondary infertility.

The semen fluid Parameters of male partners of infertile couples are characterized based on the WHO 2010 criteria for seminal fluid analysis.

Among them, about two third, 75.4\% (227/301) of the study population had at least one abnormal parameter. While, $24.6 \%$ (74/301) of them had normal seminal fluid parameters. Figure 1 show the proportion of normal and abnormal parameters.

Table 2 shows the semen characteristics among male partners of infertile couples. Parameters were characterized based on the WHO 2010 criteria for seminal fluid analysis. 18.3\% of males had Hypospermia with a semen volume less than $1.5 \mathrm{ml}$, 47.5\% had Azoospermia with no sperm cells demonstrated in their semen samples. Another $15.6 \%$ and $2.7 \%$ had Oligospermia and Cryptospermia with less than $15 \times 10^{6}$ sperm cells and $1 \times 10^{6}$ sperm cells per ml respectively. Up to $43.1 \%$ of them had Asthenospermia with a motility of less than $40 \%$ and $60.8 \%$ had Teratospermia with morphology of less than 4 . It is noteworthy that $32.6 \%$ had astheno-terato-zoospermia and $18.1 \%$ had oligo-astheno-terato-zoospermia as multiple pathologies per semen sample.

Table 3 shows the risk factors assessed among male partners of patients managed for infertility. Among them, 5.3\%, 4.3\% and 5.8\% had smoked cigarettes, consumed alcohol and had childhood mumps respectively. While, 5.0\%, 7.3\% and $4.3 \%$ were diabetic, hypertensives on medications, had had previous groin surgery respectively. Another $3.0 \%$ and $7.0 \%$ of them had trauma to the groin and had been treated for a sexually transmitted diseases respectively. There is statistical significant difference between age and semen volume at $\mathrm{p}$-value $=0.01$ as $100 \%$ of those aged 24 years and below has normal volume, while 25 years and

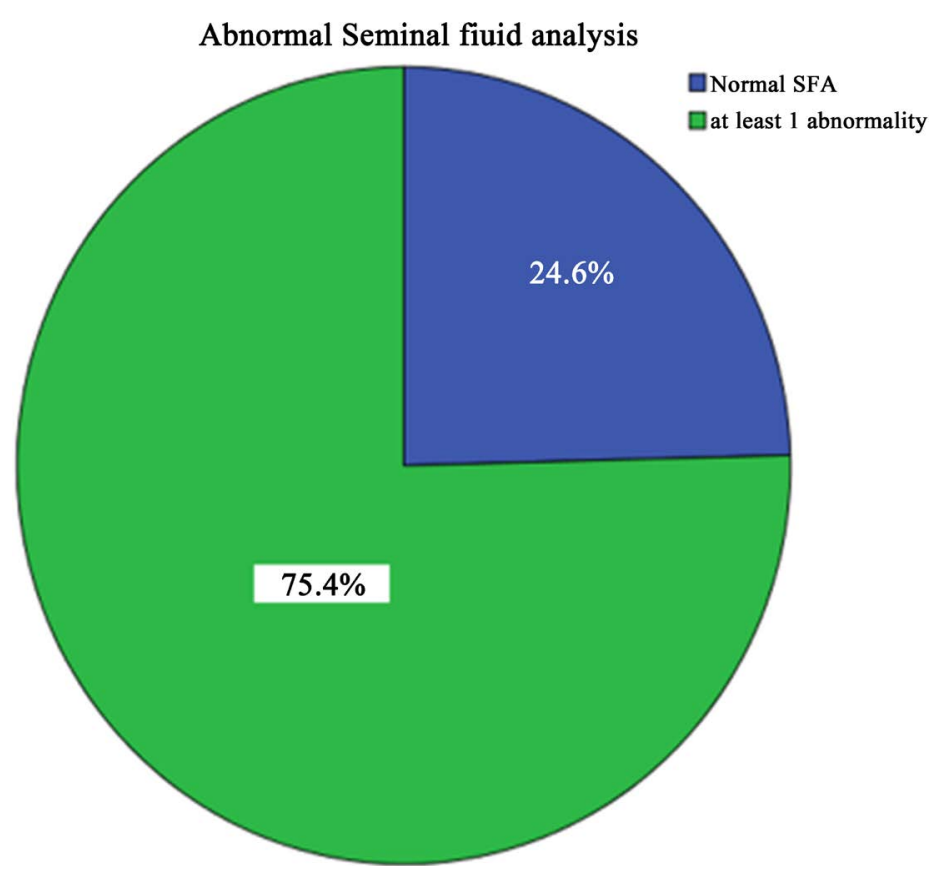

Figure 1. Proportion of normal and abnormal parameters among male partners. 
Table 2. Semen parameters amongst male partners of the infertile couples.

\begin{tabular}{|c|c|c|}
\hline Characteristic & Frequency & Percentage (\%) \\
\hline \multicolumn{3}{|l|}{ Semen volume } \\
\hline Volume $<1.5 \mathrm{ml}$ & 55 & 18.3 \\
\hline Volume $>1.5 \mathrm{ml}$ & 246 & 82.7 \\
\hline Total & 301 & 100 \\
\hline \multicolumn{3}{|l|}{ Seminal fluid count } \\
\hline Azoospermia & 143 & 47.5 \\
\hline Cryptospermia & 8 & 2.7 \\
\hline Oligospermia & 47 & 15.6 \\
\hline Normal count & 103 & 34.2 \\
\hline Total & 301 & 100 \\
\hline \multicolumn{3}{|l|}{ Motility } \\
\hline Asthenospermia (motility < 40\%) & 130 & 43.1 \\
\hline Motility $>40 \%$ & 171 & 56.8 \\
\hline Total & 301 & 100 \\
\hline \multicolumn{3}{|l|}{ Morphology } \\
\hline Teratospermia $<4 \%$ & 183 & 60.8 \\
\hline Normal morphology & 118 & 39.2 \\
\hline Total & 301 & 100 \\
\hline \multicolumn{3}{|l|}{ Combined characteristics } \\
\hline Asthenoteratozospermia & 74 & 32.6 \\
\hline Oligoasthenospermia & 3 & 1.3 \\
\hline Oligoteratospermia & 3 & 1.3 \\
\hline Oligoasthenoteratozospermia & 41 & 18.1 \\
\hline Isolated abnormalities & 107 & 47.1 \\
\hline Total & 227 & 100 \\
\hline
\end{tabular}

above have variable percentages of hypospermia. There is also significant association with leucospermia at $\mathrm{p}=0.02$ as about $3 / 4 \mathrm{TH}$ of those within 25 to 44 years have leucospermia. There is statistically significant association between groin trauma and sperm count at $\mathrm{p}$-value $=0.04$ as $100 \%$ of those with of trauma have azoospermia as against $49 \%$ in those without. In addition, $70.5 \%$ have leucospermia and that is statistically significant at $p$-value $=0.0 .02$. It is important to note that there is statistically significant relationship between previous groin surgery and sperm count at p-value $=0.01$ as up to $92 \%$ of subjects have azoospermia as against $49 \%$ of none. There is also significant association between alcohol consumption and sperm count at $\mathrm{p}$-value $=0.01$ as $18 \%$ of those who consumed alcohol have cryptospermia as against $1.9 \%$ of those who do not. Among those who had childhood mumps, $79 \%$ have azoospermia and $14 \%$ have cryptospermia as against $14.7 \%$ and $2.2 \%$ respectively for those who did not. This is also statistically significant at $\mathrm{p}$-value $=0.02$. There is also significant association between educational status and leucospermia at $\mathrm{p}$-value $=0.04$ as $100 \%$ of those with primary education have leucospermia. However, there is no significant association between hypertension, diabetes and sexually transmitted infection. 
Table 3. Risk factors in relation to semen parameters.

\begin{tabular}{|c|c|c|}
\hline Risk factor & Frequency & Percentages (\%) \\
\hline \multicolumn{3}{|l|}{ Age group } \\
\hline$<24-34$ & 100 & 33.2 \\
\hline $35-54$ & 194 & 64.5 \\
\hline $55-\geq 65$ & 7 & 2.4 \\
\hline Smoked & 16 & 5.3 \\
\hline Not smoked & 285 & 94.7 \\
\hline Consume alcohol & 18 & 5.8 \\
\hline No alcohol & 283 & 94.2 \\
\hline History of mumps & 13 & 4.3 \\
\hline No history & 288 & 95.7 \\
\hline Diabetes mellitus & 15 & 5.0 \\
\hline No diabetes & 286 & 95.0 \\
\hline Hypertension & 22 & 7.3 \\
\hline No hypertension & 279 & 92.7 \\
\hline History of groin surgery & 13 & 4.3 \\
\hline No groin trauma & 288 & 95.7 \\
\hline History of trauma to the groin & 9 & 3.0 \\
\hline No groin trauma & 292 & 97.0 \\
\hline History of sexually transmitted infection & 21 & 7.0 \\
\hline No sexually transmitted infection & 280 & 93.0 \\
\hline Total & 301 & 100 \\
\hline
\end{tabular}

\section{Discussion}

This study revealed a prevalence of male infertility accounting for $34.4 \%$. The finding of male partner contribution to infertility is in conformity with $20 \%$ $40 \%$ [3] reported earlier.

In this study, $65 \%$ of the study population had primary infertility and $35 \%$ had secondary infertility. The findings in this study is different from an earlier study in the same centre by Panti [6] where $32.8 \%$ and $67.2 \%$ were reported for primary and secondary infertility respectively. The study was among male partners of women attending the gynaecology clinic [6] while the index study is among infertile male partners of couples attending both gynaecology and urology clinics hence the possible disparity. It is also contrary to $19.6 \%$ and $80.4 \%$ for primary and secondary infertility reported by Olajubu [2], 46\% and $54.11 \%$ [16], and $22.5 \%$ and $77.5 \%$ [17] for primary and secondary infertility in similar studies in south western Nigeria, south eastern Nigeria.

This study demonstrates abnormal semen quality in up to $75.4 \%$ of the male partners of couples seeking medical attention for their inability to conceive in our environment. This is higher than $31.8 \%$ [18], 64\% [16] and 58\% [19] in similar studies in South West, South East and North Western Nigeria respectively. It 
was slightly above $70 \%$ of men having abnormal semen parameters reported in Abeokuta [20] This high figure could be attributable to the study area being a referral centre from the primary and secondary institutions for urologic conditions to the urology and gynaecologic conditions to the gynaecologic clinics.

Oligospermia and Asthenospermia are seen in $15.6 \%$ and $43.1 \%$ of the study population. This was less than $20.64 \%$ and $60.3 \%$ reported for Oligospermia and Asthenozospermia in a similar study in North western Nigerian [21], 25.6\% but higher than 11.5\% reported for Oligospermia and Asthenozospermia in Ile-ife, South western Nigeria [18]. It is also in conformity with 15.3 but higher than $3.97 \%$ in a Port-Harcourt for Oligospermia and Asthenozospermia respectively.

Abnormalities in semen volume are seen in 55 participants in this study with a percentage of $18.3 \%$ having a volume of less than $1.5 \mathrm{mLs}$. This is less than $23.8 \%$ in an earlier study in the same location [6] and $49.3 \%$ reported in south eastern [22] Nigeria but more than 7.3\% reported by Nwafia in Enugu, Nigeria [23]. In this study, $47.5 \%$ of the study population are Azospermic. This reported value is more than $8.8 \%$ reported in a study in Sagamu Nigeria [2], 2.6\% in a south eastern Nigeria [22] and 26.98\% in in Jigawa, North western Nigeria [21]. It is however, similar to $48.2 \%$ of Azospermic males reported in Ibadan Oyo, south western Nigeria [24].

Furthermore, $15 \%$ and $4 \%$ was reported for oligospermia and Asthenozospermia in Abeokuta [22] whose values are also lower than the index study. Sample size and laboratory influence may be responsible for the disparities across centres [22]. Moreover, the stringent measures and close supervision of both semen collection and different laboratory techniques may also contribute to the disparities [22]. This is so because some studies proposed $10 \times 10^{6} / \mathrm{ml}$ as the lower limit rather than of $15 \times 10^{6} / \mathrm{ml}$ [1] [22] [25]. This alters with lack of standardization.

Oligo-Astheno-zospermia, Oligo-terato-zospermia and Oligo-Astheno-teratozospermia (OAT syndrome) was seen in $1.3 \%, 1.3 \%$ and $18.1 \%$ of male participants in this study. This is less than $4.2 \%, 3.5 \%$ and $21.9 \%$ respectively in a similar study in Ibadan [24] Nigeria, and $12.7 \%, 33.3 \%$ and $33.3 \%$ in another study in North-west [21]. Owolabi reported 3.2\%, 2.3\% for Oligoasthenozospermia and Oligoteratozospermia respectively [18]. These were almost same with that reported in this study. The percentage of Oligo-Astheno-terato-zospermia (OAT syndrome) was $2.1 \%$ in an Ile-ife study [14]. This was less than $18.1 \%$ reported in this study. Figures of $23.8 \%, 9.8 \%$ and $11.20 \%$ were reported for Oligoasthenozospermia, Oligoteratozospermia and Oligoasthenoteratozospermia in a similar study in south western Nigeria [20]. These were more than the findings in this study for the percentage of the population of men that had Oligoasthenozospermia and Oligoteratozospermia but less for those that had Oligoasthenoteratozospermia (OAT Syndrome).

There is association between some the identified risk factors and the seminal fluid parameters. These include: age, educational status, smoking, alcohol consumption, history of childhood mumps, and prior groin surgeries and trauma to 
the groin. This is similar to several other studies that showed a significant relationship between male factor infertility and smoking, alcohol consumption, varicocele, childhood mumps and prior groin surgeries [1] [7] [25]. All (100\%) of those aged 24 years and below has normal volume, while 25 years and above have variable percentages of hypospermia. This could be explained by the fact that their sperm cells are still very young and likely exposed to risks that may hamper their parameters. This contrary to what was reported by Akhter [8]. So also those within 25 to 44 years and all of those with primary level of education have leucospermia. This could be explained by likelihood of infection which might had occurred sub-clinically or answers not correctly volunteered due to fear of being stigmatized.

Azoospermia is also associated with groin surgery as almost all developed it. This could be as a result of obstructive cause. It is similar what most authors reported depending on the type of surgery [1] [7] [8] [11] [25]. Alcohol consumption and childhood mumps are associated with cryptospermia, in addition mumps cause azoospermia in affected subjects. These findings are consistent with many other authors. However, there is no significant association between hypertension, diabetes and sexually transmitted infection. In the case of diabetes and hypertension, this contrary to impaired count and motility earlier reported in diabetic patients [10]. In addition to a study that reported association between hypertension and male infertility, performed on hypertension and he concluded that various antihypertensives may be the main implicating factors [15].

\section{Conclusion}

This study showed a high rate of abnormal semen quality of male partners of infertile couples in our environment with only $24.6 \%$ having normal semen parameters. This is an indication for the need to focus on the management of these conditions to reduce the scourge of infertility in our environment. Further studies are necessary in this environment to elucidate and classify the roles played by the various causes of male factor infertility.

\section{Limitations}

As result of culture and health seeking behavior not all couples agreed to performing seminal fluid analysis and therefore, affects correlation with risk factors with regards to seminal fluid parameters. Among those that agreed, not all case notes were retrieved for review because this is a retrospective study and therefore may alter the outcome of the result. Some of the identified risk factors such as antihypertensive were not assessed which is better obtained with case control study.

\section{Conflicts of Interest}

The authors declare no conflicts of interest regarding the publication of this paper. 


\section{References}

[1] Omo-Aghoja, L. (2015) Male Factor Infertility. In: Omo-Aghoja, L., Ed., Infertility and Assisted Conception in the Tropics, 1st Edition, Delta Reproductive Health Initiative and Research Centre, Sapele Delta State, 39-50.

[2] Olajubu, F.A., Mope, D.-A., Osinupebi, O.A. and Jagun, O.E. (2013) Seminal Fluid Characteristics of Men Attending Infertility Clinic of a Teaching Hospital. Open Journal of Medical Microbiology, 3, 1-4. https://doi.org/10.4236/ojmm.2013.31001

[3] Bhaduri, N., Sarkar, A.P., Dewasi, N. and Ghosh, K.T. (2015) Abnormalities in Semen Analysis among Male Partners of Infertile Couples: A Study in a Tertiary Care Level Hospital of West Bengal, India. International Journal of Reproduction, Contraception, Obstetrics and Gynecology, 4, 100-102. https://doi.org/10.5455/2320-1770.ijrcog20150219

[4] Hamilton, M. (2012) Infertility. In: Edmonds, K.D., Ed., Dewhurst's Textbook of Obstetrics and Gynaecology. 8th Edition, John Wiley \& Sons, London, 567-579. https://doi.org/10.1002/9781119979449.ch45

[5] Idrissa, A. (2005) Infertility. In: Kwawukume, E.Y. and Emuveyan, E.E., Eds., Comprehensive Gynaecology in the Tropics. Graphic Packaging Limited, Accra, 333-345.

[6] Panti, A.A. and Sununu, Y.T. (2014) The Profile of Infertility in a Teaching Hospital in North Western Nigeria. Sahel Medical Journal, 17, 7-11. https://doi.org/10.4103/1118-8561.129145

[7] Niederberger, C.S. (2016) Male Infertility. In: Wein, A.J., Kavoussi, L.R., Partin, A.W. and Peters, C.A., Eds., Campbell-Walsh Urology, 12th Edition, Elsevier, Philadelphia, USA, 1781-1844.

[8] Akhter, A., Chowdury, L., Akhter, M. and Haque, S. (2019) Risk Factors Analysis for Abnormal Semen Characteristics in Sub-Fertile Male. Medicine Today, 31, 31-35. https://doi.org/10.3329/medtoday.v31i1.40319

[9] Delfing, M., Imbrogno, N., Elia, J., Capogreco, F. and Mazzilli, F. (2007) Prevalence of Diabetes Mellitus in Male Partners of Infertile Couples. Minerva Urologica e Nefrologica, 59, 131-135.

[10] Vignon, F., Le Faou, A., Montagnon, D., et al. (1991) Comparative Study of Semen in Diabetic and Healthy Men. Diabetes \& Metabolism, 29, 350-354.

[11] Chia, S.E., Lim, S.T., Tay, S.K. and Lim, S.T. (2000) Factors with Male Infertility: A Case Study of 218 Infertile and 240 Fertile Men. British Journal of Obstetrics and Gynaecology, 107, 55-56. https://doi.org/10.1111/j.1471-0528.2000.tb11579.x

[12] Hasan, H., Yildirim, A., Can, C., Turgat, M., Tanir, H.M., Senses, T. and Shahin, F. (2006) Effects of Smoking on Semen Parameters of Men Attending an Infertile Clinic. Clinical and Experimental Obstetrics \& Gynecology, 33, 19-22.

[13] Adentji, R.A., Olagemi, O., Okeniola, M.A. and Aimakhu, C.O. (2003) Pattern of Semen Analysis of Male Partners of Infertile Couples at the University College Hospital, Ibadan. West African Journal of Medicine, 22, 243-245. https://doi.org/10.4314/wajm.v22i3.27959

[14] Omorah, W.E., Egbunike, G.N. and Ladipo, O.A. (1985) Classification of the Semen of the Male Partner of Infertile Nigerian Couples. Andrology, 17, 257-261. https://doi.org/10.1111/j.1439-0272.1985.tb00999.x

[15] Guo, D., Li, S.F., Behr, B. and Eisenberg, M.L. (2017) Hypertension and Male Fertility. World Journal of Men's Health, 35, 59-64.

https://doi.org/10.5534/wjmh.2017.35.2.59 
[16] Ugwuja, E.I., Ugwu, N.C. and Ejikeme, B.N. (2008) Prevalence of Low Sperm Count and Abnormal Semen Parameters in Male Partners of Women Consulting at Infertility Clinic in Abakaliki Nigeria. African Journal of Reproductive Health, 12, 67-73.

[17] Sule, J.O., Erigbali, P. and Eruom, L. (2008) Prevalence of Infertility in Women in a South Western Nigerian Community. African Journal of Biomedical Research, 11, 225-227. https://doi.org/10.4314/ajbr.v11i2.50716

[18] Owolabi, A.T., Fashuba, O.B. and Oguniyi, S.O. (2013) Semen Quality of Male Partners of Infertile Couples in Ile-Ife, Nigeria. The Nigerian Journal of Clinical Practice, 16, 37-40. https://doi.org/10.4103/1119-3077.106729

[19] Yusuf, T.S., Panti, A.A., Ekele, B.A. and Nwobodo, E.I. (2013) Semen Analysis of Infertile Males in Sokoto State North Western Nigeria. Caliphate Medical Journal, 1, 11-16.

[20] Chukwunyere, C.F., Awonuga, D.O., Ogo, C.N., Nwadike, V. and Chukwunyere, K.E. (2015) Pattern of Seminal Fluid Analysis in Male Partners of Infertile Couples Attending the Gynaecology Clinic at Federal Medical Centre Abeokuta. Nigerian Journal of Medicine, 24, 131-136.

[21] Ugwa, E.A., Ashimi, A., Abubakar, M. and Obadire, S. (2015) Poor Semen Parameters among Infertile Couples Presenting at a Gynaecologic Clinic of Federal Medical Centre Birnin Kudu North-Western Nigeria. Niger Medicial Journal, 56, 283-286. https://doi.org/10.4103/0300-1652.169746

[22] Ugboma, E. (2012) Pattern of Seminal Fluid Analysis among Infertile Couples in a Secondary Health Facility in South-Eastern Nigeria. Research in Obstetrics and Gynaecology, 1, 15-18.

[23] Nwafia, W.C., Igweh, J.C. and Udebuani, I.N. (2006) Semen Analysis of Infertile Igbo Mates in Enugu Eastern Nigeria. Nigerian Journal of Physiological Sciences, 21, 67-70.

[24] Olatunji, O.A. and Sule-Odu, A.O. (2003) The Pattern of Infertility Cases at a University Hospital. West African Journal of Medicine, 22, 205-207. https://doi.org/10.4314/wajm.v22i3.27950

[25] Faraj, K. (2017) Male Infertility. https://emedicine.medscape.com/article/436829-overview 